\title{
ESTIMATION OF PULMONARY RESISTANCE BY REPETITIVE INTERRUPTION OF AIRFLOW
}

\author{
By JOHN A. CLEMENTS, JOHN T. SHARP,* RUDOLPH P. JOHNSON \\ AND JAMES O. ELAM \\ (From the Clinical Investigation Branch, Directorate of Medical Research, Army \\ Chemical Center, Md.; the Department of Anesthesiology, Roswell Park \\ Memorial Institute, Buffalo, N.Y.; and the Department of Medi- \\ cine, Buffalo General Hospital, Buffalo, N. Y.)
}

(Submitted for publication December 29, 1958; accepted February 6, 1959)

It is often desirable in the study of pulmonary function to know the frictional or resistive forces associated with movement of the lungs and flow of gas in the airways. The magnitude and sign of these forces, expressed as resistive pressure differences, change with the rate and direction of volume displacement, expressed as flow. The ratio of resistive pressure difference to flow is termed pulmonary resistance and includes the "viscous resistance" of the lung tissue and the "viscous and turbulent resistance" of the airways. It does not include elastic and inertial effects of the lungs and their contained air, nor does it include mechanical effects of the chest wall, diaphragm and functionally related structures involved in respiratory motion. Defined in this way pulmonary resistance relates to the quality and quantity of moving lung and to patency of the airway as a whole.

Several methods exist for the estimation of pulmonary resistance. The most direct involves the measurement of intrapleural pressure, airflow and tidal volume. The resistive pressure gradient is that component of intrapleural pressure remaining after subtraction of the pressure necessary to maintain the lung statically at a given volume. When related to airflow it determines pulmonary resistance. A less direct but safer and more practicable technique substitutes esophageal pressure for intrapleural pressure (1). Still less direct but more convenient is the interrupter method in which the rapidly equilibrated pressure at the mouth following sudden obstruction of flow is taken as a measure of the nonelastic component of transpulmonary pressure. The validity of this method depends upon the assumptions that pres-

\footnotetext{
* This work was done during tenure of an Established Investigatorship of the American Heart Association.
}

sure recorded at the mouth rises to equal alveolar pressure (as altered) when motion of air ceases, and that intrapleural pressure does not appreciably change as a result of airflow interruption. Thus, the interrupter method is expected to measure the sum of airway and lung tissue resistance. Several investigators have designed apparatus for this type of resistance measurement and have interpreted their results variously $(2,3,4)$. Mead and Whittenberger examined the technique critically, setting forth the theoretical basis and comparing it with the esophageal balloon method (5). In their group of healthy subjects, the method of single interruption slightly overestimated pulmonary resistance.

The present investigation evaluates repetitive interruption of flow as a means of determining pulmonary resistance using a simple portable apparatus. This communication deals with details of the method and its comparison with two other methods of measuring pulmonary resistance.

\section{METHOD AND THEORY OF METHOD}

The apparatus. ${ }^{1}$ The repetitive interrupter consists of two concentric metal tubes having radial slots $90^{\circ}$ apart (Figure 1). As the inner tube rotates, airflow is switched on and off ten times per second for equal intervals of time. A third concentric tube restricts the egress of gas and forms the nonlinear flowmeter. The transition time between flow and interruption is short compared to the halfcycle time. As the subject breathes through the interrupter, pressure and flow rapidly equilibrate in the open and closed intervals so that the oscillographic tracing of mouth pressure exhibits "square waves" (Figure 2). The lower plateau $\left(P_{1}\right)$ in the tracing measures the pres-

1 A direct-writing instrument using the interrupter principle and arranged to give a plot of pulmonary resistance against exhaled volume is available from Meadowbrook Instrument Company, 1440 Carol Road, Meadowbrook, Pa. 


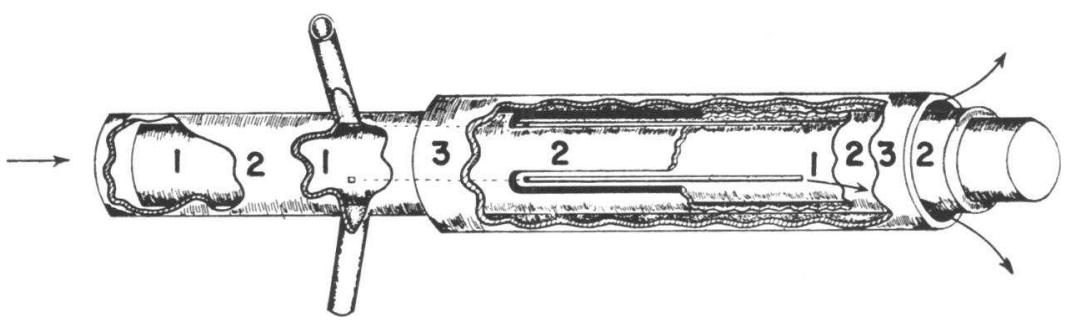

Fig. 1. Rotary Valve

Air flows from left to right through stainless steel rotor (1), radially through slots in rotor and brass stator (2) and from left to right through annular space between stator and brass sleeve (3). Rotor is turned at a constant speed of $150 \mathrm{rpm}$. Scanning holes at left end of rotor connect pressure taps at left end of stator to airway, one at the middle of open phase, the other at the middle of closed phase.

sure drop in the nonlinear flowmeter during flow. The upper plateau gives the alveolar pressure at "equilibrium" $\left(P_{2}\right)$ when flow is stopped; the difference between the plateaus is taken as a measure of the nonelastic pressure drop in the lungs and airways $(\Delta \mathrm{P})$. Since pulmonary inertance can be neglected, the pressure change at the mouth is equal to the pulmonary resistive pressure gradient, provided intrapleural pressure does not change as a result of interruption.

Nonlinear flow measurement. In the following paragraphs these symbols will be used: $F$, flow; $\Delta P$, the resistive pressure gradient; $R_{p}$, the coefficient of pulmonary resistance (including viscous and turbulent components); $R_{v}$, a coefficient of viscous resistance; $R_{t}$, a coefficient of turbulent resistance; $P_{1}$, the pressure gradient across the nonlinear flowmeter; and $R_{c}$, the coefficient of resistance of the nonlinear flowmeter.

The motion of air and tissues is made up of viscous tissue motion, laminar (viscous) airflow and turbulent airflow. Where flow is viscous, the resistive pressure difference is linearly related to airflow $\left(\Delta P=R_{v} \times F\right)$. Where flow is turbulent the resistive pressure gradient is approximately proportional to the square of flow ( $\Delta \mathrm{P}=$ $\left.R_{t} \times F^{2}\right)$. When viscous and turbulent flow exist in combination, the resistive pressure gradient is related to some power of flow between 1 and $2\left(\Delta P=R_{p} \times F^{n}\right.$, $1<\mathrm{n}<2)$. Ainsworth and Eveleigh (6) made a noteworthy contribution to the understanding of pulmonary resistance by finding that the formulation, $\Delta P=R_{p} \times F^{1.6}$, was adequate to describe normal individuals. After showing that the nonlinearity of the pressure-flow relationship was characteristic of the population rather than of the individual they were able to express differences between the individuals and change within an individual following a broncho-motor drug entirely in the magnitude of the resistance coefficient. By constructing a flowmeter, the nonlinear characteristic of which matched that of the respiratory tract, they could estimate pulmonary resistance from the ratio of internal (pleura-to-mouth) and external (nonlinear. flowmeter) resistive pressure gradients, thus ingeniously simplifying the interrupter method.
Since the nonlinear flowmeter is constructed according to the relationship :

$$
P_{1}=R_{c} F^{1.6},
$$

and since the relationship of pressure to flow in the subject's lungs and airway is

$$
\Delta \mathrm{P}=\mathrm{R}_{\mathrm{P}} \times \mathrm{F}^{\mathbf{1 . 6}},
$$

it follows that

$$
\frac{\Delta \mathrm{P}}{\mathrm{P}_{1}}=\frac{\mathrm{R}_{\mathrm{P}} \times \mathrm{F}^{1.6}}{\mathrm{R}_{\mathrm{c}} \times \mathrm{F}^{1.6}} \text {, or } \mathrm{R}_{\mathrm{P}}=\frac{\mathrm{R}_{\mathrm{c}} \times \Delta \mathrm{P}}{\mathrm{P}_{1}} .
$$

Thus, measurement of the pressure ratio $\Delta P / P_{1}$ and calibration of the nonlinear flowmeter (determination of $R_{c}$ ) suffice for calculation of pulmonary resistance.

Recording of pressure. While the pressure ratio could be determined from oscillographic tracings, it was desirable to simplify the technique further. Consequently, the pressure leads were valved in such a way that pressure was applied to the manometers during only the middle third of each half-cycle and the manometer sealed off for the remainder of the cycle. One lead registered mouth

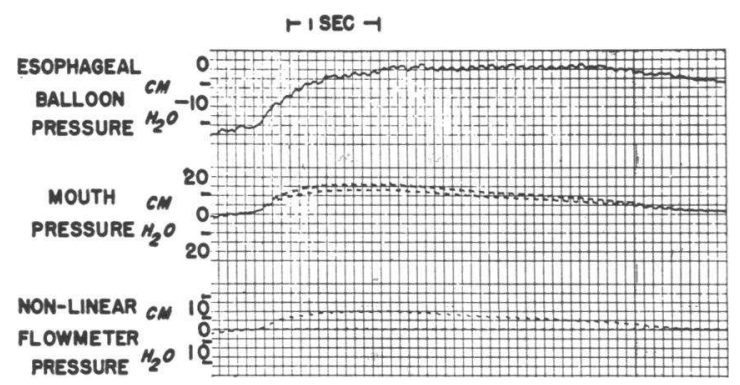

Fig. 2. Esophageal Pressure, Mouth Pressure and Airflow DURING Repetitive Interruption in ExPIRATION

The "square wave" pattern of mouth pressure is shown. Small oscillations occur in esophageal pressure at a frequency of 10 cycles per second. 


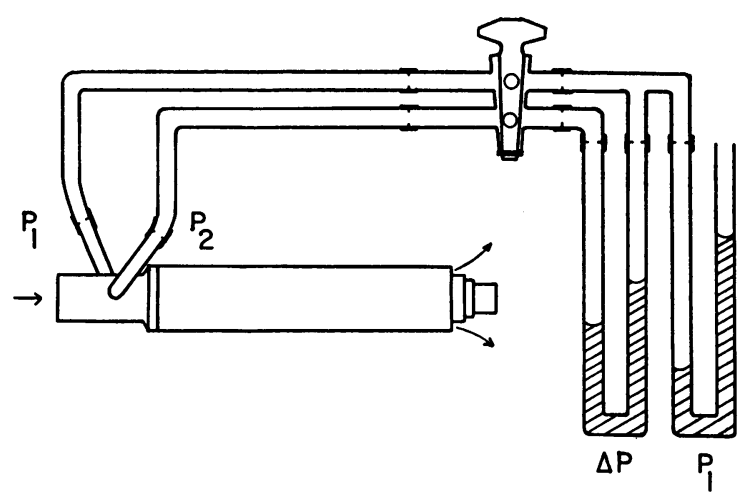

Fig. 3. This Figure Shows the Manner of Connecting Manometers through a Double Stopcock to The Rotating Valve

pressure during the middle third of the interrupted phase $\left(\mathrm{P}_{2}\right)$ and the other lead registered pressure during the middle third of the flow phase $\left(P_{1}\right)$. The valving was accomplished by placing "scanning holes" of precise dimensions and location in the rotating and stationary inner cylinders. Thus, with steady average flow, the pressures in the two valved or "scanned" leads are constant at the plateau values and may be indicated on slowly responding systems such as water manometers. The scanned pressures have been recorded in several ways for indicating pulmonary resistance. Three will be described.

If a double stopcock is interposed in the pressure leads, it can be closed during the subject's exhalation into the interrupter, thus holding the plateau pressures in the manometers for accurate reading (Figure 3 ). $P_{1}$ appears on one manometer; $P_{2}$ minus $P_{1}$ or $\Delta P$ is registered on the other (differential) manometer. The ratio is calculated and used as above. By plotting $\Delta \mathrm{P}$ against $\mathrm{P}_{1}$ at different flows one can discover how well pulmonary resistance and flow meter resistance are matched in nonlinearity (Figure 4). This arrangement was used in Comparison 2.

If the scanned pressure is applied to balanced strain gauges connected in opposition through a galvanometer one can zero the galvanometer by changing the supply current in the gauge registering the $\mathrm{P}_{1}$ pressure (Figure 5). With proper calibration, the milliameter in the $P_{1}$ gauge supply may be made to read pulmonary resistance directly. This arrangement permits the determination of resistance with changing flow, is faster in use and requires less cooperation from the subject. This arrangement was used in Comparison 1.

The $\Delta \mathrm{P}$ and $\mathrm{P}_{1}$ pressures (scanned) may be applied to strain gauges and recorded on an oscillograph as was done in Comparison 3. This permitted simultaneous volume recording so that comparisons of esophageal balloon and interrupter methods could be made at the same lung volume.

Calibration. The entire instrument was calibrated at a mean flow of $0.5 \mathrm{~L}$. per second (half-cycle flow $1.0 \mathrm{~L}$. per second, as air flowed only half the time) by con- ducting air from a flowmeter through a high resistance into a $4 \mathrm{~L}$. anesthesia bag which served as a lung analogue. At the wide neck of this bag a variable resistance was attached and distal to this, the repetitive interrupter. Resistance was varied from 0.2 to $15 \mathrm{~cm} . \mathrm{H}_{2} \mathrm{O}$ per $\mathrm{L}$. per second and at each setting measured first at a steady flow of $1 \mathrm{~L}$. per second using a differential water manometer. It was then measured by the repetitive interrupter using water manometers. Pressure in the anesthesia bag, analogous to alveolar pressure in this calibration scheme, varied less than $0.1 \mathrm{~cm} . \mathrm{H}_{2} \mathrm{O}$ on interruption.

\section{PROCEDURES}

Comparison 1 (Table I). Ten patients were prepared for elective thoracotomy with Demerol $\otimes$, Pentothal Sodium ${ }^{\circledR}$ and succinylcholine chloride. After intubation with a cuffed tracheal tube, they were maintained on a nitrous oxide-oxygen mixture and on succinylcholine by intravenous drip. The tracheal tube was connected by a valve either through the anesthesia machine or through the apparatus for the measurement of resistance. Following dissection down to the parietal pleura, a curved cannula with several perforations was inserted into the intrapleural "space." Ten to twenty cc. of air was admitted to the chest via the cannula and transpulmonary pressure recorded using a differential strain gauge and direct-writing oscillograph. The airway was connected to a screen pneumotachometer and airflow recorded. The flow signal was integrated electrically to generate a tracing of tidal volume. Recordings were made of passive expirations and resistance calculated by the method of Otis, Fenn and Rahn $(7,8)$. Alternately, passive expirations were directed into the repetitive interrupter for determination of resistance using strain gauges and the ratio circuit shown in Figure 5. The resistance of the

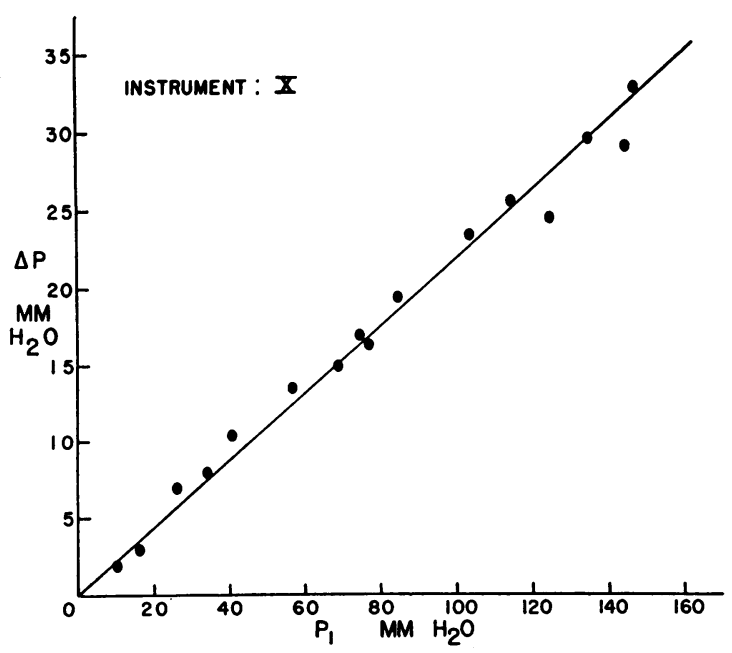

Fig. 4. Plot of "Pulmonary Resistive" Pressure Gradient $(\Delta \mathrm{P})$ against Flowmeter Pressure Gradient $\left(\mathrm{P}_{1}\right)$ over the Flow Range 0.1 to 1.9 L. Per Second 


\section{RATIO INDICATOR}

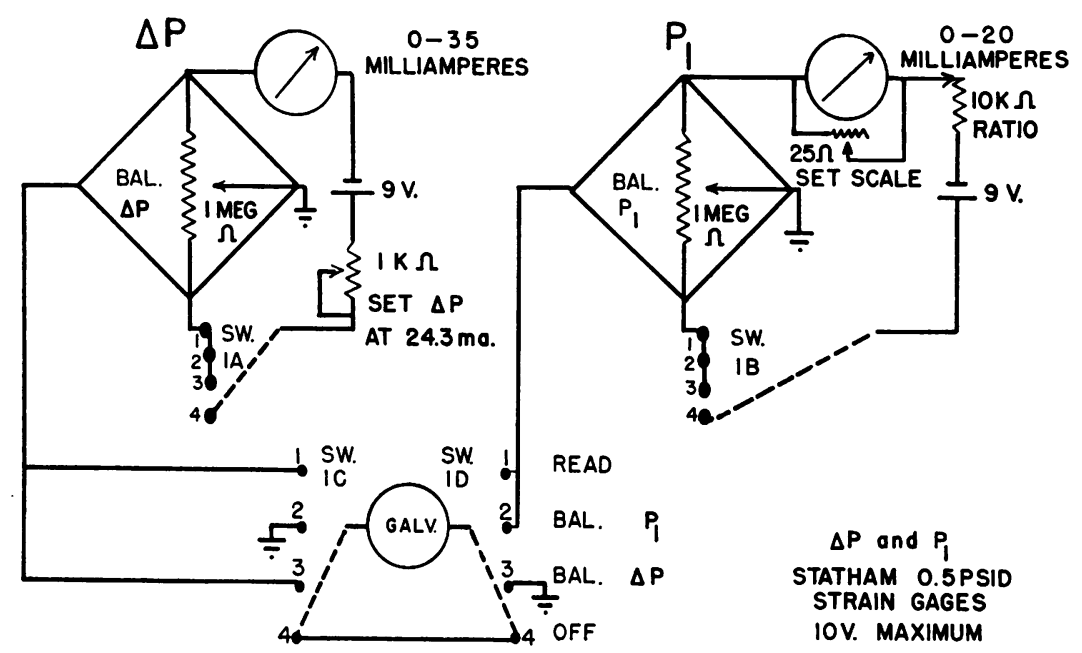

Fig. 5. Circuit for Determining the Ratio of Two Pressures, using 0.5 psid Strain Gauges

Proper adjustment allows pulmonary resistance to be read directly from the 20 ma. meter.

endotracheal tube was measured and subtracted from both estimates of pulmonary resistance.

Comparison 2 (Table II). In a second study resistance values by repetitive interruption and by the esophageal pressure method were compared in 11 healthy young adults. The subjects were studied in the sitting position and transpulmonary (esophagus-to-mouth) pressure, tidal volume and airflow were recorded continuously during spontaneous breathing. The nonelastic component of transpulmonary pressure at the instant when flow was equal to one $\mathrm{L}$. per second was taken as the value of pulmonary resistance. On a subsequent day, resistance was detemined by repetitive interruption using water

TABLE I

Comparison 1: Pulmonary resistance determined by repetitive interruption compared with resistance calculated from intrapleural pressure, volume and flow recordings during passive expiration in ten anesthetized patients with pulmonary tuberculosis

\begin{tabular}{lcc}
\hline \hline & $\begin{array}{c}\text { Resistance by } \\
\text { interrupter } \\
\text { method }\end{array}$ & $\begin{array}{c}\text { Resistance by } \\
\text { intrapleural } \\
\text { pressure } \\
\text { method }\end{array}$ \\
\hline Patient & $c m . H_{2} \mathrm{O} /$ L./sec. & $\mathrm{cm} . \mathrm{H}_{2} \mathrm{O} / \mathrm{L} . / \mathrm{sec}$. \\
M. L. & 4.6 & 4.8 \\
F. C. & 7.7 & 8.3 \\
E. N. & 3.9 & 3.7 \\
A. W. & 6.8 & 7.1 \\
H. C. & 2.3 & 3.3 \\
J. C. & 2.8 & 2.5 \\
W. J. & 2.9 & 2.5 \\
E. M. & 3.2 & 2.9 \\
A. R. & 5.5 & 5.0 \\
W. R. & 5.0 & 4.6 \\
\hline
\end{tabular}

TABLE II

Comparison 2: Pulmonary resistance in eleven healthy adults as determined by measurement of esophageal pressure and by repetitive interruption * $\uparrow$

\begin{tabular}{lllc}
\hline \hline & $\begin{array}{c}\text { Esophageal } \\
\text { balloon } \\
\text { method } \\
\pm \text { S. E. }\end{array}$ & $\begin{array}{c}\text { Interrupter } \\
\text { method } \\
\pm \text { S. E. }\end{array}$ & p \\
\hline J. C. & $2.17 \pm 0.07$ & $2.00 \pm 0.07$ & $>0.05$ \\
J. S. & $1.92 \pm 0.07$ & $1.13 \pm 0.09$ & $<0.05$ \\
G. G. & $1.84 \pm 0.10$ & $2.24 \pm 0.24$ & $>0.05$ \\
R. W. & $2.01 \pm 0.12$ & $1.61 \pm 0.06$ & $<0.05$ \\
E. B. & $1.80 \pm 0.11$ & $1.79 \pm 0.06$ & $>0.05$ \\
B. B. & $1.99 \pm 0.12$ & $2.21 \pm 0.32$ & $>0.05$ \\
W. O. & $1.22 \pm 0.11$ & $1.84 \pm 0.03$ & $<0.05$ \\
J. A. C. & $1.48 \pm 0.12$ & $1.19 \pm 0.06$ & $<0.05$ \\
W. J. W. & $2.18 \pm 0.05$ & $2.97 \pm 0.04$ & $<0.05$ \\
A. B. & $0.89 \pm 0.14$ & $2.14 \pm 0.9$ & $<0.05$ \\
M. B. M. & $3.54 \pm 0.15$ & $2.21 \pm 0.09$ & $<0.05$ \\
Group averages & 1.91 & 1.94 & \\
\end{tabular}

* Means and standard errors were calculated from twenty resistance values by the esophageal pressure method and ten values by the interrupter method.

$\dagger$ Resistance in $\mathrm{cm}$. $\mathrm{H}_{2} \mathrm{O}$ per L. per second.

manometers to determine values of $\Delta \mathrm{P}$ and $\mathrm{P}_{1}$ (Figure 3 ). Ten breaths were analyzed by each method yielding 20 resistance values by the esophageal pressure method and 10 values by the interrupter method. Averages and standard errors are shown in Table II.

Comparison 3 (Table III). The lung volumes at which interrupter measurements were made in Comparison 2 were not determined. Because resistance varies considerably with lung volume $(1,9,10)$, it seemed likely 
TABLE III

Comparison 3: Pulmonary resistance by esophageal pressure method and interrupter method in six normal subjects*

\begin{tabular}{lcccc}
\hline \hline & \multicolumn{2}{c}{ Resistance } & \multicolumn{1}{c}{ Per cent } \\
\cline { 2 - 4 } Subject & $\begin{array}{c}\text { Esophageal } \\
\text { balloon } \\
\text { method }\end{array}$ & $\begin{array}{c}\text { Inter- } \\
\text { rupter } \\
\text { method }\end{array}$ & $\begin{array}{c}\text { difference } \\
\text { between } \\
\text { methods }\end{array}$ & p \\
\hline G. G. & 1.53 & 1.84 & $17 \%$ & $>0.05$ \\
J.S. & 1.21 & 1.41 & $14 \%$ & $<0.05$ \\
D. R. & 1.79 & 1.91 & $6 \%$ & $>0.05$ \\
D. G. & 3.09 & 3.21 & $4 \%$ & $>0.05$ \\
A. B. & 0.91 & 1.07 & $15 \%$ & $<0.05$ \\
M. M. & 2.81 & 2.92 & $4 \%$ & $>0.05$
\end{tabular}

* Measurements made at the same lung volumes are compared.

that the variation between methods observed in several subjects occurred because measurements at different lung volumes had been compared. For this reason, a third comparison was done on six normal subjects in which volumes were recorded and resistances by the two methods compared at the same lung volume. The results of this comparison are shown in Table III.

\section{RESULTS}

The reproducibility of interrupter values of resistance is shown in Tables II, IV and V. Table II shows the resistance values for each subject in Comparison 2 and the standard error of 10 observations in each subject. Table IV presents typical data from one normal subject. Table $\mathrm{V}$ shows the resistance change effected by bronchodilator in a subject with mild asthma.

The relationship between resistive pressure and flow in the 11 subjects matched satisfactorily the relationship of resistive pressure to flow across

TABLE IV

Ten determinations of pulmonary resistance by repetitive interruption in one healthy adult subject (J.C.) showing typical variation

\begin{tabular}{|c|c|c|}
\hline$\Delta \mathrm{P}$ & $P_{1}$ & $\begin{array}{c}\text { Resistance by } \\
\text { interrupter }\end{array}$ \\
\hline \multirow[t]{2}{*}{$\begin{array}{c}m m . \mathrm{H}_{2} \mathrm{O} \\
27.6 \\
32.8 \\
30.4 \\
25.5 \\
26.8 \\
32.0 \\
32.8 \\
19.2 \\
29.7 \\
33.7\end{array}$} & $\begin{array}{c}m m . \mathrm{H}_{2} \mathrm{O} \\
106.1 \\
97.2 \\
94.6 \\
83.0 \\
83.9 \\
101.3 \\
80.2 \\
65.1 \\
100.8 \\
122.0\end{array}$ & $\begin{array}{c}\text { cm. } \mathrm{H}_{2} \mathrm{O} / \mathrm{L} . / \mathrm{sec} . \\
1.60 \\
2.18 \\
2.06 \\
1.95 \\
2.06 \\
2.03 \\
2.72 \\
1.87 \\
1.87 \\
1.72\end{array}$ \\
\hline & & $\begin{array}{ll}\text { an } & 2.00 \\
21 & \text { S. E. } 0.07\end{array}$ \\
\hline
\end{tabular}

the nonlinear flowmeter as determined by inspection of the plot of pulmonary resistive pressure $(\Delta P)$ against flowmeter pressure $\left(P_{1}\right)$ at various expiratory flow rates. This confirms the findings of Ainsworth and Eveleigh (6) in a larger group of healthy young adults. A typical result is shown in Figure 4 where the flow range extends from 0.1 to $1.9 \mathrm{~L}$. per sceond.

\section{Comparison 1}

Comparison 1 in which resistance calculated from intrapleural pressure is compared with the resistance determined by repetitive interruption in anesthetized, intubated patients is summarized

TABLE V

Pulmonary resistance in one subject suffering from mild asthma*

\begin{tabular}{|c|c|c|c|c|}
\hline$\Delta \mathbf{P}$ & $\mathbf{P}_{1}$ & $\Delta \mathrm{P} / \mathrm{P}_{1}$ & $\mathbf{R}_{1}$ & Average \\
\hline \multicolumn{5}{|c|}{ Before Isuprel @ } \\
\hline $\begin{array}{l}44.4 \\
45.8 \\
48.4 \\
57.3 \\
68.2\end{array}$ & $\begin{array}{r}98.4 \\
104.0 \\
83.4 \\
102.5 \\
123.8\end{array}$ & $\begin{array}{l}0.452 \\
0.431 \\
0.582 \\
0.534 \\
0.551\end{array}$ & $\begin{array}{l}3.04 \\
2.91 \\
4.07 \\
3.69 \\
3.82\end{array}$ & 3.50 \\
\hline \multicolumn{5}{|c|}{5 minutes after Isuprel $\circledast$} \\
\hline $\begin{array}{l}33.0 \\
26.5 \\
23.6 \\
28.7 \\
21.7\end{array}$ & $\begin{array}{r}117.0 \\
85.5 \\
74.4 \\
88.7 \\
95.0\end{array}$ & $\begin{array}{l}0.282 \\
0.310 \\
0.318 \\
0.324 \\
0.228\end{array}$ & $\begin{array}{l}1.72 \\
1.96 \\
2.03 \\
2.07 \\
1.32\end{array}$ & 1.82 \\
\hline
\end{tabular}

* Measurements taken before and five minutes after inhalation of an aerosol of Isuprel $($.

in Table I. Even though the resistance of the endotracheal tube and valve was subtracted from all values, the remaining (pulmonary) resistance tended to be above the normal range, perhaps because of bronchospastic reaction to the presence of a cuffed tube in the trachea or to the presence of pulmonary disease, or both. The correlation even at the higher values of resistance is good:

\section{Comparison 2}

The first column of Table II summarizes measurements by the esophageal ballon method in 11 normal subjects; the second column summarizes measurements on the same subjects by the interrupter technique. Though there was reasonable agreement between the two methods, significant differences were encountered in seven of the 11 subjects. 


\section{Comparison 3}

In all six subjects the interrupter method overestimated resistance (average 10.5 per cent). In two of the six the difference was significant at the 5 per cent level (Table III). In all subjects both methods showed the same changes in resistance with changing lung volume, resistance increasing as lung volume decreased (Figure 6).

The best correlation with the "standard" method was obtained in Comparison 1 on anesthetized relaxed patients in whom the upper airway was bypassed by an intratracheal tube and in whom intrapleural pressure rather than esophageal pressure was recorded. Variation of upper airway resistance beyond the subject's conscious control or discrepancy between esophageal and pleural pressures or both of these factors may contribute to the greater variation between methods observed in Comparisons 2 and 3.

Comparison 3 in which resistances were compared at similar lung volumes gave a better correlation between methods than Comparison 2 where the lung volume at which the interrupter values were obtained was not accurately known. This suggests that the variation of resistance as a function of lung volume accounts for part of the variation between methods observed in Comparison 2 .

\section{DISCUSSION}

Analysis of this method of measuring pulmonary resistance and of its sources of error requires that one consider the several components of pulmonary resistance and determine what pressure and flow measurements made at the mouth mean in terms of forces and motion within the whole respiratory system. In addition one should attempt to define the range over which there can be reasonable confidence in the values. In the following sections these considerations will be amplified.

\section{Infuence of thorax}

As shown by Mead and Whittenberger (5) pressure changes on single interruption are small in the esophagus and presumably in the pleural space. They have presented evidence that this is due to relatively high thoracic compliance which

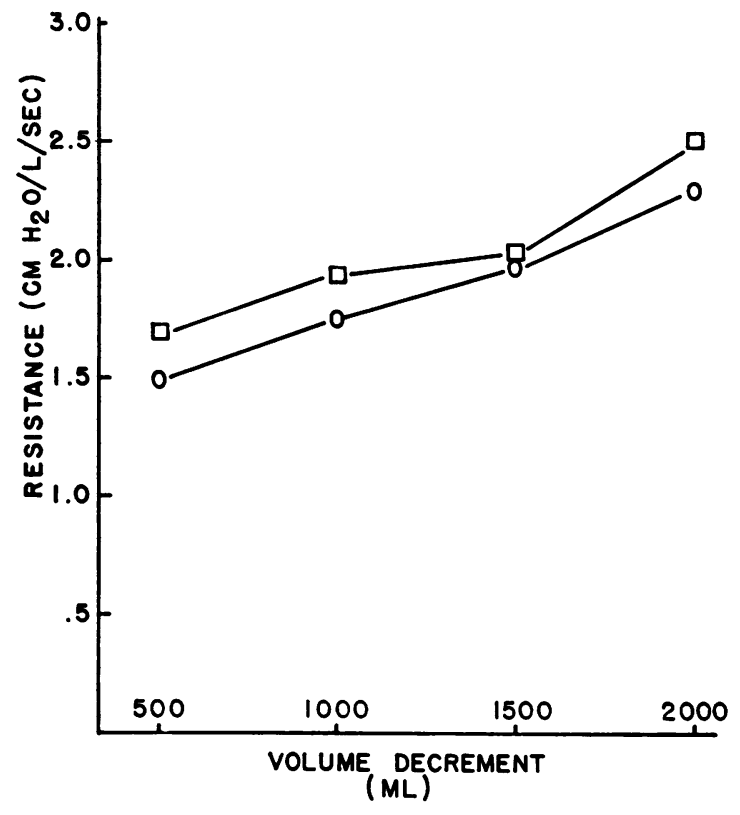

Fig. 6. Pulmonary Resistance by Repetitive InterRuption (SQUares) AND BY Calculation From Esophageal Pressure (Circles)

Abscissa, volume exhaled after maximal inspiration; ordinate, resistance.

absorbs momentum from the diaphragm and keeps intrapleural pressure nearly constant during interruption. Similarly, only small oscillations occur in esophageal pressure during repetitive interruption (Figure 2). Thus the thorax, diaphragm and abdominal contents act together at 10 cycles per second as a low impedance pressure source and only a small component of "extrapulmonary resistance" is added to that of the lungs and airways under the usual conditions of measurement. This added component amounts to 0.1 to $0.2 \mathrm{~cm} . \mathrm{H}_{2} \mathrm{O}$ per $\mathrm{L}$. per second and increases the change of alveolar pressure with interruption. It results in an overestimation of pulmonary resistance by 5 to 10 per cent. At extremes of lung volume, changes of esophageal pressure on interruption are greater than in the mid-range of volume, indicating that the thorax no longer compensates for inertance of the diaphragm and abdominal contents so effectively. This stiffening of the chest (lowered thoracic compliance) is probably due to the tension of intercostal muscles and the approach of the thorax to its volume limit, and may result in more significant overestimation of pulmonary resistance by interruption. 


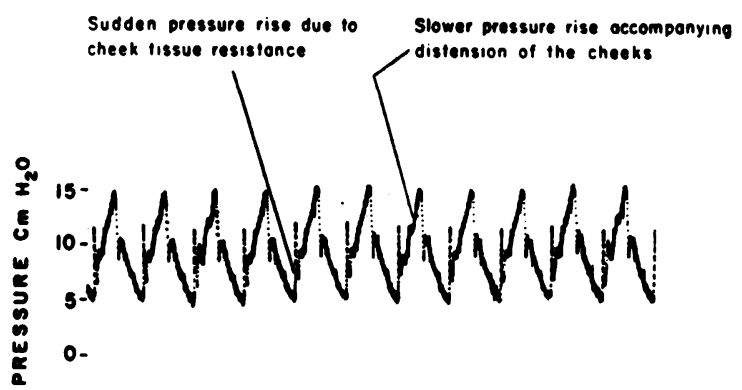

Fig. 7. Tracing of Mouth Pressure (Unscanned) in the Determination of Upper Airway Shunt Compliance and Tissue Resistance

Average airflow is $0.5 \mathrm{~L} . / \mathrm{sec}$. Glottis is closed and nares are occluded.

\section{Influence of upper airway}

It was suspected that the tissue inertance, compliance and resistance of the upper airway might be of importance. These parameters were measured in two normal subjects. This was done by conducting air into one nostril at 0.5 or at $1 \mathrm{~L}$. per second while the subject, with the other nostril and the glottis closed and with lips tightly around the mouthpiece of the interrupter, allowed air to pass from the mouth through the interrupter. Mouth pressure was recorded on an oscillograph (Figure 7) and from the tracings obtained tissue compliance and resistance of the upper airway were calculated. Compliance was $0.001 \mathrm{~L}$. per $\mathrm{cm}$. $\mathrm{H}_{2} \mathrm{O}$ and tissue resistance was $5 \mathrm{~cm} . \mathrm{H}_{2} \mathrm{O}$ per $\mathrm{L}$. per second, with cheeks relaxed. Inertance was calculated from the frequency of oscillations occurring at valve closure and found to be negligible.

Simplified electrical and pneumatic analogues were set up for clarification of the basic physical problem, using the values given in Table VI, ac- cording to the scheme of Figure 8. These analogues were arranged so that "pulmonary resistance" could be varied from 0.5 to $20 \mathrm{~cm} . \mathrm{H}_{2} \mathrm{O}$ per L. per second and estimates with steady flow compared to those with pulsating flow. It was evident from the behavior of the analogue that "shunt" compliance and resistance in the upper airway influence the pattern of mouth pressure significantly. The distensible upper airway must receive gas as pressure in the mouth rises to equal alveolar pressure during equilibration. The more distensible the upper airway (mainly the cheeks) and the greater the pulmonary resistance, the longer this equilibration requires. Fortunately, the upper airway is relatively rigid (low compliance, high tissue resistance and thus high impedance), and should permit estimation of normal pulmonary resistance within 2 per cent, judging from the behavior of the pneumatic analogue.

Figure 8 shows the extent to which the method underestimates resistance as pulmonary resistance increases. Pulsatile or interrupter resistance was calculated and compared to steady flow resistance at several levels of increased resistance. These calculations were based upon the differential equations describing pulsatile flow at $10 \mathrm{cps}$ in electrical and pneumatic analogues schematized in Figure 8. The nonlinear relationship of the pulmonary resistance pressure to flow was found to shorten the effective equilibration time and calculations taking this into account agreed with values observed in a pneumatic analogue having similar nonlinear characteristics. Further calculations assuming a linear flow-pressure relationship showed that resistance was underestimated to a greater extent than in the case of nonlinear resistance.

TABLE VI

Components with their values and units used in electrical and mechanical analogues of the respiratory system *

\begin{tabular}{|c|c|c|c|}
\hline Component & Symbol & $\begin{array}{l}\text { Mechanical (pneumatic) } \\
\text { analogue }\end{array}$ & Electrical analogue \\
\hline $\begin{array}{l}\text { Lung compliance } \\
\text { Lung gas compliance } \\
\text { Upper airway shunt compliance } \\
\text { Airway resistance } \\
\text { Lung tissue resistance } \\
\text { Pulmonary resistance }\left(\mathbf{R}_{\mathbf{a}}+\mathbf{R}_{\mathbf{1}}\right) \\
\text { Upper airway shunt resistance } \\
\text { Flowmeter resistance } \\
\text { Pulmonary gas inertance }\end{array}$ & $\begin{array}{l}\mathrm{C}_{\mathrm{i}} \\
\mathrm{Cg}_{\mathrm{g}} \\
\mathrm{Cm}_{\mathrm{m}} \\
\mathrm{R}_{\mathrm{a}} \\
\mathrm{R}_{\mathbf{1}} \\
\mathrm{R}_{\mathrm{p}} \\
\mathrm{R}_{\mathrm{m}} \\
\mathrm{R}_{\mathrm{s}} \\
\mathrm{I}_{\mathrm{a}}\end{array}$ & $\begin{array}{l}0.200 \mathrm{~L} . / \mathrm{cm} . \mathrm{H}_{2} \mathrm{O} \\
0.004 \mathrm{~L} . / \mathrm{cm} . \mathrm{H}_{2} \mathrm{O} \\
0.001 \mathrm{~L} . / \mathrm{cm} . \mathrm{H}_{2} \mathrm{O} \\
1.5 \mathrm{to} 20 \mathrm{~cm} . \mathrm{H}_{2} \mathrm{O} \mathrm{L} . / \mathrm{sec} . \\
0.5 \mathrm{~cm} . \mathrm{H}_{2} \mathrm{O} \mathrm{L} . / \mathrm{sec} . \\
2.0 \mathrm{~cm} . \mathrm{H}_{2} \mathrm{O} \mathrm{L} . / \mathrm{sec} . \\
5.0 \mathrm{~cm} . \mathrm{H}_{2} \mathrm{O} \mathrm{L} . / \mathrm{sec} . \\
6.4 \mathrm{~cm} . \mathrm{H}_{2} \mathrm{O} \mathrm{L} . / \mathrm{sec} . \\
0.01 \mathrm{~cm} . \mathrm{H}_{2} \mathrm{O} \mathrm{L} . / \mathrm{sec} . / \mathrm{sec} .\end{array}$ & $\begin{array}{l}200 \text { microfarads } \\
4 \text { microfarads } \\
1 \text { microfarad } \\
1,500 \text { to } 20,000 \text { ohms } \\
500 \text { ohms } \\
2,000 \text { ohms } \\
5,000 \text { ohms } \\
6,400 \text { ohms } \\
10 \text { henries }\end{array}$ \\
\hline
\end{tabular}

* The components of pneumatic and electrical analogues based on known physical properties of the human respiratory system. Both analogues follow the schematic diagram shown in Figure 8. 


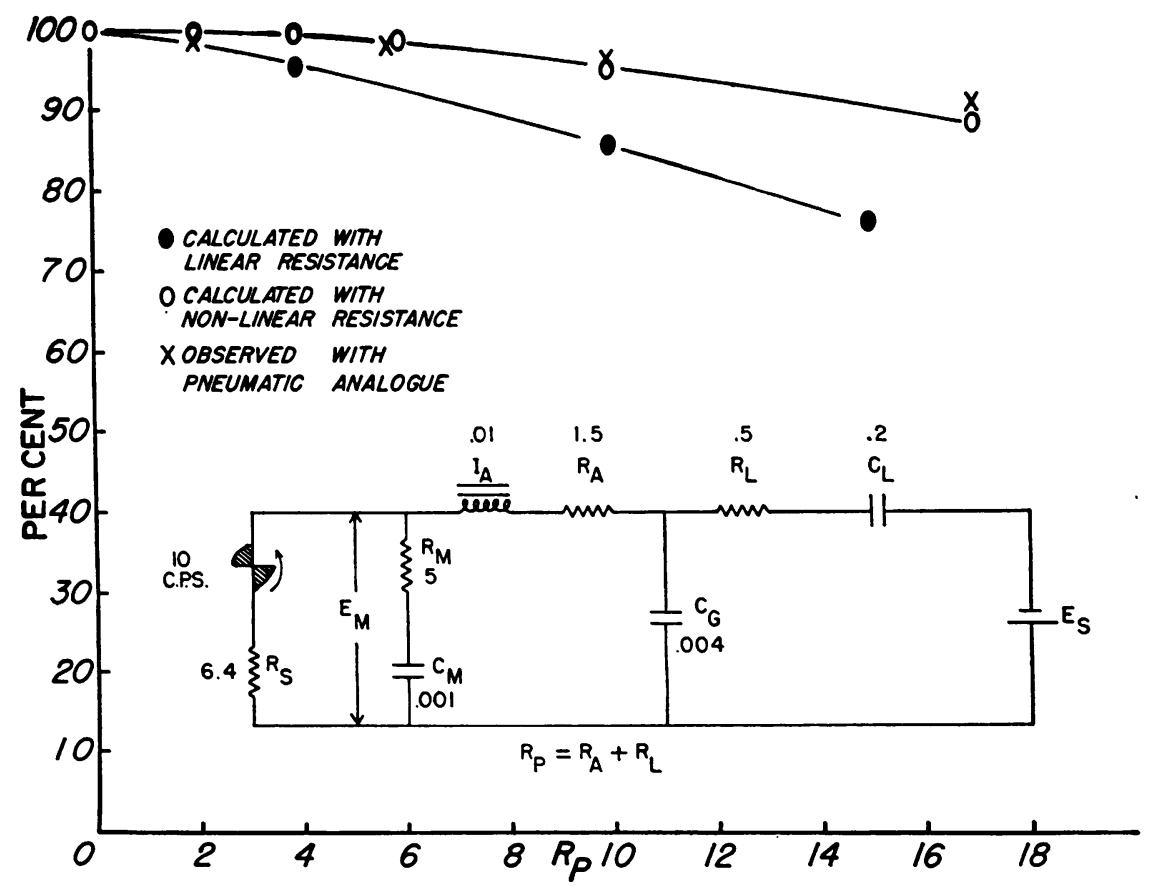

Fig. 8. Plot of "Pulmonary Resistance" Measured at 1 L. Per Second Steady Flow and 0.5 L. Per Second Pulsatile Flow in a Pneumatic Analogue ConStructed According to the Diagram Shown in the Insert

Parameters are based on actual measurements of mechanical properties of the human respiratory system. Ordinate, percentage of steady flow resistance measured by interrupter technique; abscissa, steady flow resistance at 1 L. per second. Symbols with units and electrical equivalents are defined in Table VI.

Thus the nonlinearity of pulmonary resistance increases the apparent accuracy of the interrupter method. The degree of nonlinearity used in calculations and the analogue was comparable to that measured in healthy adults. Figure 8 shows that pulmonary resistance up to $15 \mathrm{~cm} . \mathrm{H}_{2} \mathrm{O}$ per $\mathrm{L}$. per second in the analogue is measured with a deficit of less than 10 per cent.

To what extent linearity is altered in patients with elevated resistance and the effect of such change on the validity of the interrupter method remains to be elucidated. As Mead, Lindgren and Gaensler (11) and Fry, Ebert, Stead and Brown (12) have shown, pressure equilibration following interruption of airflow is comparatively slow in patients with obstructive emphysema. Cheng, Godfrey and Shepard have used repetitive interruption and recording of exhaled volume in studies of patients with obstructive pulmonary disease (13). They have found resistance-volume patterns that suggest the mechanisms of obstruction and are hence of diagnostic value. The failure of complete pressure equilibration following interruption of flow in these patients did not seriously detract from the clinical usefulness of the method.

\section{SUM MARY}

1. A simple technique for estimation of lung and airway resistance has been developed using repetitive interruption of airflow and nonlinear flowmetering.

2. The method is satisfactory with respect to reproducibility of values and is a valid method for measuring resistance as judged by comparison with standard methods.

3. The theory of the method has been briefly explored with special attention to the influence of the thorax and effect of upper airway properties. The physical properties of the thorax cause slight overestimation of resistance and this effect is increased at the extremes of lung volume. The effect of upper airway properties is to cause 
underestimation of resistance: This effect is accentuated by increased distensibility of upper airways especially when pulmonary resistance is high.

4. It is concluded from resistance measurements on human subjects and from studies on respiratory analogues that the inherent error of the method ranges from about $+0.2 \mathrm{~cm} . \mathrm{H}_{2} \mathrm{O}$ per L. per second in the normal to about $-1.5 \mathrm{~cm}$. $\mathrm{H}_{2} \mathrm{O}$ per L. per second at $15 \mathrm{~cm} . \mathrm{H}_{2} \mathrm{O}$ per L. per second.

5. It is pointed out that the method may develop larger errors in nonhomogeneous obstructive pulmonary disease.

\section{ACKNOWLEDGMENTS}

The authors gratefully acknowledge the help of Dr. Richard Kiefer and Dr. Bruce Armstrong of Baltimore Veterans Hospital, who made possible measurements of intrapleural pressure in patients prepared for thoracotomy; of Mr. Milton Wirth who furnished valuable suggestions in design and construction of the repetitive interrupter and of Dr. Merl D. Nefzger of the Department of Biostatistics of the Roswell Park Memorial Institute.

\section{REFERENCES}

1. Mead, J., and Whittenberger, J. L. Physical properties of human lungs measured during spontaneous respiration. J. appl. Physiol. 1953, 5, 779.

2. von Neergaard, K., and Wirz, K. Die messung der strömmungswiderstände in den atemwegen des menschen, insbesondere bei asthma und emphysem. Z. klin. Med. 1927, 105, 51.

3. Vuilleumier, P. Uber eine method zur messung des intraalveolären druckes und der strömungswider- stände in den atemwegen des menschen. Z. klin. Med. 1943-44, 143, 698.

4. Otis, A. B., and Proctor, D. F. Measurement of alveolar pressure in human subjects. Amer. J. Physiol. 1948, 152, 106.

5. Mead, J., and Whittenberger, J. L. Evaluation of airway interruption technique, as a method for measuring pulmonary air flow resistance. J. appl. Physiol. 1954, 6, 408.

6. Ainsworth, M. A., and Eveleigh, J. A method of estimating lung-airway resistance in humans (1952); Porton technical papers 320 and 331 : An instrument for determining lung-airway resistance (1953). Chemical Defense Experimental Establishment, Porton, Wiltshire, England.

7. Otis, A. B., Fenn, W. O., and Rahn, H. Mechanics of breathing in man. J. appl. Physiol. 1950, 2, 592.

8. Clements, J. A., and Elam, J. O. Estimation of lungairway resistance by repetitive interruption of airflow (abstract). Amer. J. Physiol. 1955, 183, 604.

9. Clements, J. A., and Johnson, R. P. Relationship between respiratory deadspace and resistance and estimation of lung tissue resistance (abstract). Fed. Proc. 1956, 15, 36.

10. Briscoe, W. A., and DuBois, A. B. Effect of lung volume on airway conductance (abstract). Amer. J. Physiol. 1956, 187, 588.

11. Mead, J., Lindgren, I., and Gaensler, E. A. The mechanical properties of the lungs in emphysema. J. clin. Invest. 1955, 34, 1005.

12. Fry, D. L., Ebert, R. V., Stead, W. W., and Brown, C. C. The mechanics of pulmonary ventilation in normal subjects and in patients with emphysema. Amer. J. Med. 1954, 16, 80.

13. Cheng, T. O., Godfrey, M. P., and Shepard, R. H. Relationship between pulmonary resistance and the state of inflation of the lungs in normal subjects and in subjects with obstruction of the airways. J. appl. Physiol. In press. 